\title{
Application of Fuzzy Soft Set Theory in Day to Day Problems
}

\author{
Krishna Gogoi \\ Devicharan Barua Girls \\ College, Jorhat, Assam
}

\author{
Alock Kr. Dutta \\ Bahona College, Bahona, \\ Jorhat, Assam
}

\author{
Chandra Chutia \\ Jorhat Institute of Science and \\ Technology, Jorhat, Assam
}

\begin{abstract}
In our daily life we often face some problems in which the right decision making is highly essential .But most of these cases we become confused about the right solution .To obtain the best feasible solution of these problems we have to consider various parameters relating to the solution. For this we can use the best mathematical tool called Fuzzy soft set theory .In this paper we select a burning problem for the parents and successfully applied the Fuzzy soft set theory in decision making.
\end{abstract}

\section{KEYWORDS}

Fuzzy set_1, Fuzzy Softset, Decision Matrix

\section{INTRODUCTION}

The most appropriate theory for dealing with uncertainty in the theory of Fuzzy Sets developed by Zedeh [ 1 ] in 1965. A Fuzzy Set is defined by its membership function, whose values are defined on the interval $[0,1]$.

Pawlak introduced rough set theory [ 3 ] in 1982, which is another significant approach to modeling vagueness. This theory has been successfully applied to many field such as machine learning, data mining, data analysis, medicine etc.

Presently work on the Soft Set theory is progressing rapidly. Maji et al. [4] described the application of Soft Set theory for decision-making problems by using rough sets. Chen et al., [ 13 ] introduce a new definition of Soft Set parameterization reduction and compare his definition to the related concept of attributes reduction in rough set theory.

Rosenfeld [14] proposed the concept of Fuzzy group in order to establish the algebraic structure of Fuzzy Sets. Rough groups were defined by Biswas et al. [15] and have studied the algebraic properties of rough sets. Before going to the main objectives of our study we need the following notations for better understanding the topic

\subsection{Important Notations}

Let us recall the notation of Fuzzy Sets as follows :

For every set $A \subset X$, define its indicator function $\mu_{A}$

$$
\begin{array}{r}
\mu_{A}(x)=1, \text { if } x \in A \\
0, \text { if } x \notin A
\end{array}
$$

A Fuzzy Set F is described by its membership function $\mu_{A}$. For every $x \in X$, this function associates a real number $\mu_{F}(x)$ in the internal $[0,1]$. The number $\mu_{F}(x)$ is interpreted for the point as a degree of belonging $x$ to the Fuzzy Set F.

Let $\mathrm{F}$ and $\mathrm{G}$ be two Fuzzy Set and $\mu_{F}, \mu_{G}$ are their membership functions. The complement $\mathrm{CF}$ is defined by its membership functions as

$$
\mu_{C F}(x)=1-\mu_{F}(x)
$$

The union $F \cup G_{\text {can be defined by any one of the }}$ following membership functions.

$$
\begin{aligned}
& \mu_{F \cup G}(x)=\max \left\{\mu_{F}(x), \mu_{G}(x)\right\} \\
& \mu_{F \cup G}(x)=\mu_{F}(x)+\mu_{G}(x)-\mu_{F}(x) \cdot \mu_{G}(x) \\
& \mu_{F \cup G}(x)=\min \left\{1, \mu_{F}(x), \mu_{G}(x)\right\}
\end{aligned}
$$

The intersection $F \cap G$ can be defined by any one of the following membership function.

$$
\begin{aligned}
& \mu_{F \cup G}(x)=\min \left\{\mu_{F}(x), \mu_{G}(x)\right\} \\
& \mu_{F \cap G}(x)=\mu_{F}(x) \cdot \mu_{G}(x) \\
& \mu_{F \cap G}(x)=\max \left\{0, \mu_{F}(x)+\mu_{G}(x)-1\right\}
\end{aligned}
$$

Though the Fuzzy Set is progressing rapidly, but there exists a difficulty; how to set the membership function in each particular case.

To avoid such difficulties, Molodtsov [ 2 ] use an adequate parameterization. $\mathrm{U}$ be an initial universal set and $\mathrm{E}$ be a set of parameters. The pair (F, E) is called a Soft Set (over U) if and only if $F$ is a mapping of $E$ into the set of all subsets of $U$. Hence the Soft Set is a parameterized family of subsets of the set U. Every set $F(\varepsilon), \varepsilon \in E$, from this family may be considered as the set of - element of the Soft Set (F, E).

\section{APPLICATION OF SOFT SET THEORY}

Molodtsov [ 2 ] presented some applications of the soft set theory in several directions viz. study of smoothness of functions , game theory, operations research, Riemannintegration, Perron integration, probability, theory of measurement, etc. In this section, we present an application of soft set theory in a decision making problem with the help of rough approach [3] .Let us now formulate our problem as follows:

Problem: Let $\mathrm{U}=\left\{\mathrm{c}_{1}, \mathrm{c}_{2}, \mathrm{c}_{3}, \mathrm{c}_{4}, \mathrm{c}_{5}, \mathrm{c}_{6}, \mathrm{c}_{7}\right\}$ be the set of seven cars and

$E=\{$ expensive, fuel efficiency, spacious , maintenance free , ecofriendly, high security measure $\}$ are set of parameters .Let $(\mathrm{F}, \mathrm{P})$ be a soft set representing the "suitable cars" given by $(F, P)=\left\{\right.$ expensive cars $=\left\{c_{2}, c_{3}, c_{5}, c_{7}\right\}$, fuel efficiency $=$ $\left\{\mathrm{c}_{1}, \mathrm{c}_{2}, \mathrm{c}_{3}, \mathrm{c}_{4}\right\} \quad$ spacious $=\left\{\mathrm{c}_{4}, \mathrm{c}_{5}, \mathrm{c}_{6}, \mathrm{c}_{7}\right\}$, maintenance free $=\left\{c_{2}, c_{4}, c_{6}, c_{7}\right\}$ ecofriendly $=\left\{c_{1}, c_{2}, c_{3}, c_{4}, c_{5}, c_{6}\right\}$, high security measure $\left.=\left\{c_{3}, c_{4}, c_{6}, c_{7}\right\}\right\}$

Suppose that $\mathrm{Mr} X$ wants to buy a car consisting the parameter fuel efficiency, spacious , ecofriendly ,high security measure which forms the subset 
$P=\{$ fuel efficiency, spacious, ecofriendly ,high security measure \}of the set $\mathrm{E}$.

The problem is to select the car which is suitable with the choice parameters set by $\mathrm{Mr} \mathrm{X}$.

\section{Solution:}

Let us first make a tabular representation of the problem:

Consider the soft set $(\mathrm{F}, \mathrm{P})$ where $\mathrm{P}$ is the choice parameter of Mr X.

$$
\text { Suppose } \begin{aligned}
\mathrm{h}_{\mathrm{ij}} & =1 \text { if } \mathrm{h}_{\mathrm{i}} \in \mathrm{F}(\mathbf{\epsilon}) \\
& =0 \text { if hi } \in \mathrm{F}(\mathbf{\epsilon})
\end{aligned}
$$

\begin{tabular}{|c|cccc|}
\hline & $\mathbf{e}_{1}$ & $\mathbf{e}_{2}$ & $\mathrm{e}_{3}$ & $\mathbf{e}_{4}$ \\
\hline $\mathrm{C}_{1}$ & 1 & $\mathbf{0}$ & $\mathbf{1}$ & $\mathbf{0}$ \\
$\mathrm{C}_{2}$ & 1 & 0 & 1 & 0 \\
$\mathrm{C}_{3}$ & 1 & 0 & 1 & 1 \\
$\mathrm{C}_{4}$ & 1 & 1 & 1 & 1 \\
$\mathrm{C}_{5}$ & $\mathbf{0}$ & 1 & 1 & 0 \\
$\mathrm{C}_{6}$ & 0 & 1 & 1 & 1 \\
$\mathrm{C}_{7}$ & 0 & 0 & 1 & 1 \\
\hline
\end{tabular}

Where $\mathbf{e}_{\mathbf{i}} \in \mathrm{P}, \mathrm{i}=1,2,3,4$

\section{REDUCT -TABLE OF A SOFT SET:}

Here $\mathrm{P}$ is subset of $\mathrm{E}$ so, $(\mathrm{F}, \mathrm{P})$ is a soft subset of $(\mathrm{F}, \mathrm{E})$

Let $\mathrm{Q}$ be a reduct of $\mathrm{P}$. Then $\operatorname{soft} \operatorname{set}(\mathrm{F}, \mathrm{Q})$ is called reduct softest of the softest $(\mathrm{F}, \mathrm{P})$

\section{Choice value of an object $C_{i}$}

The choice value of an object $\mathrm{Ci} \mathrm{U}$ is pi where

$$
\mathbf{P}_{\mathbf{i}}=\sum \mathbf{c}_{\mathrm{ij}} \quad \text {, where } \mathbf{c}_{\mathrm{ij}} \text { is the entries in the table of }
$$
reduct-softset.

Where $\mathbf{C}_{\mathbf{i}}$, in the entries in the table of reduct softest.( [13],)

\section{ALGORITHM FOR SELECTION OF CAR}

To select the car for Mr. X, the following algorithm may be followed-

1. Input the softest $(\mathrm{F}, \mathrm{E})$.

2. Input the set $\mathbf{P}$ of the choice parameter for Mr. $\mathrm{X}$,

3. Find all reduced soft sets of(F,P).

4. Choose one reduced-softset say $(F, Q)$ of $(F, P)$

5. Find $\mathbf{k}$ for which $\mathrm{P}_{\mathrm{k}}=\max \mathbf{p}_{\mathbf{i}}$

Then $\mathrm{C}_{\mathrm{k}}$ in the optional choice object of $\mathrm{K}$ has more than one value, than any one of them could be chosen by Mr. X.

Using the above algorithm we try to solve the above problem.

Here $\mathrm{P}=\left\{\mathrm{e}_{1}, \mathrm{e}_{2}, \mathrm{e}_{3}, \mathrm{e}_{4}\right\}$. From table we see that $\left\{\mathrm{e}_{1}, \mathrm{e}_{2}, \mathrm{e}_{4} ..\right\}$ is

\begin{tabular}{|c|c|c|c|c|}
\hline & $\mathbf{e}_{1}$ & $\mathbf{e}_{2}$ & $\overline{\mathbf{e}_{4}}$ & choice value \\
\hline $\mathbf{c}_{1}$ & 1 & 0 & 0 & $p_{1}=1$ \\
\hline $\mathbf{c}_{2}$ & $\mathbf{1}$ & 0 & $\mathbf{0}$ & $p_{2}=1$ \\
\hline$c_{3}$ & 1 & 0 & 1 & $p_{3}=2$ \\
\hline $\mathbf{c}_{4}$ & 1 & $\mathbf{1}$ & 1 & $\mathbf{p}_{4}=3$ \\
\hline$c_{5}$ & 0 & 1 & 0 & $p_{5}=1$ \\
\hline $\mathbf{c}_{6}$ & 0 & 1 & 1 & $p_{6}=2$ \\
\hline$c_{7}$ & $\mathbf{0}$ & 0 & 1 & $p_{7}=1$ \\
\hline
\end{tabular}
the reduct of $\mathrm{P}$.

Using choice value the reduct-soft-set can be tabulated as-
Here $\max \mathrm{p}_{\mathrm{i}}=\mathrm{p}_{4}$

\section{DECISION : Mr X can buy the car $\mathrm{c}_{4}$}

\section{Weighted table of a soft set}

Lin [ 16] introduced the theory of "W-soft set" which is weighted soft set. The weighted choice value of an object $\mathbf{c}_{\mathbf{i}}$ $\mathrm{EU}$ is $\mathbf{W} \mathbf{p}_{\mathbf{i}}$ where

$$
\mathbf{W} \mathbf{p}_{\mathbf{i}}=\sum \mathbf{d}_{\mathrm{ij}} \text { such that } \mathbf{d}_{\mathrm{ij}}=\mathbf{w}_{\mathbf{j}} \times \mathbf{e}_{\mathrm{ij}}
$$

The revised Algorithm for selection of car ---

1. Input the softset $(\mathrm{F}, \mathrm{E})$

2. Input the set $\mathrm{P}$ of choice parameter for $\mathrm{Mr} \mathrm{X}$ which is a subset of $\mathrm{E}$

3. Find all reduct-softset of (F,P)

4. Choose one reduct-softset $(\mathrm{F}, \mathrm{Q})$

5. Find weighted table of the softset $(\mathrm{F}, \mathrm{Q})$ according to the weights decided by $\mathrm{Mr} \mathrm{X}$.

6. Find $\mathrm{k}$ for which $\mathrm{Wp} \mathrm{p}_{\mathrm{i}}=\max \mathrm{Wp}$

Then $\mathbf{c}_{\mathbf{k}}$ is the optional choice object. If $\mathrm{k}$ has more than one value, then any one of them could be chosen by $\mathrm{Mr} \mathrm{X}$ by using his option .

Let us try to solve the original problem by using revised algorithm . Suppose Mr X sets the weights for the parameter as follows

fuel efficiency------------- $\mathrm{w}_{1}=0.9$
spacious--------------- $\mathrm{w}_{2}=0.7$
ecofriendly------------- $\mathrm{w}_{3}=0.6$

high security measure $-\mathrm{w}_{4}=0.5$

Using these weights the reduct-softset can be tabulated as - 


\begin{tabular}{|c|cccc|}
\hline & $\begin{array}{l}\mathrm{w}_{\mathrm{j}} \mathrm{x} \\
\mathrm{e}_{1}\end{array}$ & $\mathrm{w}_{\mathrm{j}} \mathrm{x}_{2}$ & $\mathrm{w}_{\mathrm{j}} \mathrm{x} \mathrm{e}_{4}$ & $\begin{array}{l}\text { Choce value } \\
\mathbf{W} \mathbf{p}_{\mathrm{i}}\end{array}$ \\
\hline $\mathrm{c}_{1}$ & 0.9 & 0 & 0 & 0.9 \\
$\mathrm{c}_{2}$ & 0.9 & 0 & 0 & 0.9 \\
$\mathrm{c}_{3}$ & 0.9 & 0 & 0.5 & 1.4 \\
$\mathrm{c}_{4}$ & 0.9 & 0.7 & 0.5 & 2.1 \\
$\mathrm{c}_{5}$ & 0 & 0.7 & 0 & 0.7 \\
$\mathrm{c}_{6}$ & 0 & 0.7 & 0.5 & 1.2 \\
$\mathrm{c}_{7}$ & 0 & 0 & 0.5 & 0.5 \\
& & & & \\
\hline
\end{tabular}

Here $\max \mathrm{Wp}_{\mathrm{i}}=\mathrm{Wp}_{4}$

\section{DECISION : Mr X can buy the car $\mathrm{c}_{\mathbf{4}}$}

$\mathrm{Mr} \mathrm{X}$ is facing a problem for choosing the suitable course for his son among the available courses medical, engineering ,computer application, pure science and humanities which are denoted by $\mathbf{m}, \mathbf{e}, \mathbf{c}, \mathbf{p}$ and $\mathbf{h}$ respectively. He seeks advice from four counseling agencies $\mathbf{a}_{1}, \mathbf{a}_{2}, \mathbf{a}_{3}, \mathbf{a}_{4}$.

The four agencies provided the information about the courses considering the parameters availability of seat ,future prospects , affordability, studentfriendly curriculum, job security and eligibility of the student which are denoted by $\mathbf{s}_{\mathbf{1}}, \mathbf{s}_{\mathbf{2}}, \mathbf{s}_{\mathbf{3}}, \mathbf{s}_{\mathbf{4}}, \mathbf{s}_{\mathbf{5}}$ and $\mathbf{s}_{\mathbf{6}}$ respectively.

$\mathrm{U}=\{\mathrm{m}, \mathrm{e}, \mathrm{c}, \mathrm{p}, \mathrm{h}\}$ be the set of courses for study and $\mathrm{S}=\left\{\mathrm{s}_{1}\right.$, $\left.\mathrm{s}_{2}, \mathrm{~s}_{3}, \mathrm{~s}_{4}, \mathrm{~s}_{5}, \mathrm{~s}_{6}\right\}$ be the set of parameters .

The information provided by the counseling agencies forms the fuzzy soft sets $\left(\mathrm{F}_{1}, \mathrm{~S}\right),\left(\mathrm{F}_{2}, \mathrm{~S}\right),\left(\mathrm{F}_{3}, \mathrm{~S}\right)$ and $\left(\mathrm{F}_{4}, \mathrm{~S}\right)$ over $\mathrm{U}$ where $\mathrm{F}_{1}, \mathrm{~F}_{2}, \mathrm{~F}_{3}, \mathrm{~F}_{4}$ are mappings from $\mathbf{S}$ into $\mathbf{I}^{\mathbf{U}}$, where $\mathbf{I}^{\mathbf{U}}$ is the set of all fuzzy subsets of $U$ given by the counseling agencies .

$$
\begin{aligned}
& \mathrm{F}_{1}\left(\mathrm{~s}_{1}\right)=\left\{\frac{m}{0.5}, \frac{e}{0.6}, \frac{c}{0.5}, \frac{p}{0.8}, \frac{h}{0.9}\right\} \\
& \mathrm{F}_{1}\left(\mathrm{~s}_{2}\right)=\left\{\frac{m}{0.8}, \frac{e}{0.7}, \frac{c}{0.6}, \frac{p}{0.4}, \frac{h}{0.3}\right\} \\
& \mathrm{F}_{1}\left(\mathrm{~s}_{3}\right)=\left\{\frac{m}{0.1}, \frac{e}{0.2}, \frac{c}{0.3}, \frac{p}{0.6}, \frac{h}{0.8}\right\} \\
& \mathrm{F}_{1}\left(\mathrm{~s}_{4}\right)=\left\{\frac{m}{0.3}, \frac{e}{0.4}, \frac{c}{0.5}, \frac{p}{0.4}, \frac{h}{0.8}\right\} \\
& \mathrm{F}_{1}\left(\mathrm{~s}_{5}\right)=\left\{\frac{m}{0.9}, \frac{e}{0.8}, \frac{c}{0.7}, \frac{p}{0.6}, \frac{h}{0.2}\right\} \\
& \mathrm{F}_{1}\left(\mathrm{~s}_{6}\right)=\left\{\frac{m}{0.1}, \frac{e}{0.2}, \frac{c}{0.3}, \frac{p}{0.5}, \frac{h}{0.8}\right\} \\
& \mathrm{F}_{2}\left(\mathrm{~s}_{1}\right)=\left\{\frac{m}{0.52}, \frac{e}{0.59}, \frac{c}{0.6}, \frac{p}{0.85}, \frac{h}{0.91}\right\} \\
& \mathrm{F}_{2}\left(\mathrm{~s}_{2}\right)=\left\{\frac{m}{0.79}, \frac{e}{0.75}, \frac{c}{0.65}, \frac{p}{0.43}, \frac{h}{0.25}\right\} \\
& \mathrm{F}_{2}\left(\mathrm{~s}_{3}\right)=\left\{\frac{m}{0.15}, \frac{e}{0.22}, \frac{c}{0.40}, \frac{p}{0.70}, \frac{h}{0.90}\right\} \\
& \mathrm{F}_{2}\left(\mathrm{~s}_{4}\right)=\left\{\frac{m}{0.25}, \frac{e}{0.35}, \frac{c}{0.45}, \frac{p}{0.50}, \frac{h}{0.75}\right\} \\
& \mathrm{F}_{2}\left(\mathrm{~s}_{5}\right)=\left\{\frac{m}{0.87}, \frac{e}{0.88}, \frac{c}{0.75}, \frac{p}{0.65}, \frac{h}{0.30}\right\} \\
& \mathrm{F}_{2}\left(\mathrm{~s}_{6}\right)=\left\{\frac{m}{0.13}, \frac{e}{0.22}, \frac{c}{0.35}, \frac{p}{0.49}, \frac{h}{0.85}\right\}
\end{aligned}
$$

$$
\begin{aligned}
& \mathrm{F}_{3}\left(\mathrm{~s}_{1}\right)=\left\{\frac{m}{0.55}, \frac{e}{0.63}, \frac{c}{0.54}, \frac{p}{0.75}, \frac{h}{0.91}\right\} \\
& \mathrm{F}_{3}\left(\mathrm{~s}_{2}\right)=\left\{\frac{m}{0.88}, \frac{e}{0.86}, \frac{c}{0.70}, \frac{p}{0.50}, \frac{h}{0.40}\right\} \\
& \mathrm{F}_{3}\left(\mathrm{~s}_{3}\right)=\left\{\frac{m}{0.20}, \frac{e}{0.30}, \frac{c}{0.50}, \frac{p}{0.70}, \frac{h}{0.90}\right\} \\
& \mathrm{F}_{3}\left(\mathrm{~s}_{4}\right)=\left\{\frac{m}{0.29}, \frac{e}{0.33}, \frac{c}{0.48}, \frac{p}{0.52}, \frac{h}{0.85}\right\} \\
& \mathrm{F}_{3}\left(\mathrm{~s}_{5}\right)=\left\{\frac{m}{0.85}, \frac{e}{0.84}, \frac{c}{0.78}, \frac{p}{0.65}, \frac{h}{0.23}\right\} \\
& \mathrm{F}_{3}\left(\mathrm{~s}_{6}\right)=\left\{\frac{m}{0.12}, \frac{e}{0.25}, \frac{c}{0.30}, \frac{p}{0.57}, \frac{h}{0.85}\right\} \\
& \mathrm{F}_{4}\left(\mathrm{~s}_{1}\right)=\left\{\frac{m}{0.58}, \frac{e}{0.67}, \frac{c}{0.56}, \frac{p}{0.86}, \frac{h}{0.95}\right\} \\
& \mathrm{F}_{4}\left(\mathrm{~s}_{2}\right)=\left\{\frac{m}{0.89}, \frac{e}{0.87}, \frac{c}{0.69}, \frac{p}{0.45}, \frac{h}{0.36}\right\} \\
& \mathrm{F}_{4}\left(\mathrm{~s}_{3}\right)=\left\{\frac{m}{0.19}, \frac{e}{0.27}, \frac{c}{0.34}, \frac{p}{0.57}, \frac{h}{0.89}\right\} \\
& \mathrm{F}_{4}\left(\mathrm{~s}_{4}\right)=\left\{\frac{m}{0.32}, \frac{e}{0.35}, \frac{c}{0.40}, \frac{p}{0.45}, \frac{h}{0.70}\right\} \\
& \mathrm{F}_{4}\left(\mathrm{~s}_{5}\right)=\left\{\frac{m}{0.85}, \frac{e}{0.87}, \frac{c}{0.73}, \frac{p}{0.61}, \frac{h}{0.23}\right\} \\
& \mathrm{F}_{4}\left(\mathrm{~s}_{6}\right)=\left\{\frac{m}{0.18}, \frac{e}{0.24}, \frac{c}{0.37}, \frac{p}{0.56}, \frac{h}{0.78}\right\}
\end{aligned}
$$

\section{ALGORITHM}

We shall follow the following algorithm for the solution of the problem discussed above .

1. Input the performance evaluation of courses by different counseling agencies as matrix .

2. Find the average of the corresponding entries of all the matrices in step I

3. Multiply the weightage of different courses of the guardian to the corresponding entries of each row to get the comprehensive decision matrix

4. Formulate the comparison table

5. Find the row-sums and column-sums of the comparison table

6. Obtain the score for each product and the product of with maximum score is ecommended as the best choice .

Now the matrix representation of above four fuzzy soft set $\left(\mathrm{F}_{1}, \mathrm{~S}\right),\left(\mathrm{F}_{2}, \mathrm{~S}\right),\left(\mathrm{F}_{3}, \mathrm{~S}\right)$ and $\left(\mathrm{F}_{4}, \mathrm{~S}\right)$ are as follows

\begin{tabular}{|ccccc}
0.5 & 0.6 & 0.5 & 0.8 & 0.9 \\
0.8 & 0.7 & 0.6 & 0.4 & 0.3 \\
0.1 & 0.2 & 0.3 & 0.6 & 0.8 \\
0.3 & 0.4 & 0.5 & 0.4 & 0.8 \\
0.9 & 0.8 & 0.7 & 0.6 & 0.2 \\
0.1 & 0.2 & 0.3 & 0.5 & 0.8
\end{tabular}




$\left(F_{2}, S\right)=$\begin{tabular}{cccccc}
\cline { 5 - 5 } & & & & \\
& 0.58 & 0.67 & 0.56 & 0.86 & 0.95 \\
0.89 & 0.87 & 0.69 & 0.45 & 0.36 \\
0.19 & 0.27 & 0.34 & 0.57 & 0.89 \\
0.2 & 0.35 & 0.40 & 0.45 & 0.70 \\
0.85 & 0.87 & 0.73 & 0.61 & 0.23 \\
0.18 & 0.24 & 0.37 & 0.56 & 0.78 \\
\hline
\end{tabular}

$\left(F_{3}, S\right)=\left[\begin{array}{cccccc}\right.$\cline { 5 - 5 } & & & & & \\ 0.52 & 0.59 & 0.6 & 0.85 & 0.91 \\ 0.15 & 0.22 & 0.40 & 0.70 & 0.90 \\ 0.25 & 0.35 & 0.45 & 0.50 & 0.75 \\ 0.87 & 0.88 & 0.75 & 0.65 & 0.30 \\ 0.13 & 0.22 & 0.35 & 0.49 & 0.85 \\ \hline\end{array}

$\left(F_{4}, S\right)=$\begin{tabular}{cccccc}
\cline { 5 - 6 } & & & & & \\
0.55 & 0.63 & 0.54 & 0.75 & 0.91 \\
0.20 & 0.30 & 0.50 & 0.70 & 0.90 \\
0.85 & 0.84 & 0.78 & 0.65 & 0.23 \\
0.12 & 0.25 & 0.30 & 0.57 & 0.85 \\
\hline
\end{tabular}

Taking the average of the above four fuzzy soft sets we get the performance evaluation matrix as
Suppose that $\mathrm{Mr} \mathrm{X}$ sets the preference weightage fo the different courses as

$\mathrm{W}=$

\begin{tabular}{|c|c|c|c|c|}
\hline $\mathrm{m}$ & $\mathrm{e}$ & $\mathrm{c}$ & $\mathrm{p}$ & $\mathrm{h}$ \\
\hline 0.3 & 0.3 & 0.275 & 0.1 & 0.025 \\
\hline
\end{tabular}

such that $\sum \mathbf{w}_{\mathbf{j}}=\mathbf{1}$

The comprehensive decision matrix $\mathbf{D}$ can be obtained by multiplying A row by row by the weightage matrix $\mathbf{W}$ and the transposing it as follow

$\mathbf{D}=$

\begin{tabular}{|c|c|c|c|c|c|}
\hline 0.54 & 0.84 & 0.16 & 0.29 & 0.87 & 0.13 \\
\hline 0.62 & 0.80 & 0.25 & 0.36 & 0.85 & 0.23 \\
\hline 0.55 & 0.66 & 0.39 & 0.46 & 0.74 & $\mathbf{0 . 3 3}$ \\
\hline 0.82 & 0.45 & 0.64 & 0.47 & 0.63 & 0.53 \\
\hline 0.92 & 0.33 & 0.87 & 0.78 & 0.24 & 0.82 \\
\hline
\end{tabular}

The comparison table of the above comprehensive decision matrix is

\begin{tabular}{|c|c|c|c|c|c|c|}
\hline & $\mathrm{m}$ & $\mathrm{e}$ & $\mathrm{c}$ & $\mathrm{p}$ & $\mathrm{h}$ & Row-sum \\
\hline $\mathrm{m}$ & 6 & 2 & 3 & 4 & 6 & 21 \\
\hline $\mathrm{e}$ & 4 & 6 & 3 & 6 & 6 & 25 \\
\hline $\mathrm{c}$ & 3 & 3 & 6 & 6 & 6 & 24 \\
\hline $\mathrm{p}$ & 2 & 0 & 0 & 6 & 6 & 14 \\
\hline $\mathrm{h}$ & 0 & 0 & 0 & 0 & 6 & 6 \\
\hline $\begin{array}{l}\text { Column- } \\
\text { sum }\end{array}$ & $\mathbf{1 5}$ & $\mathbf{1 1}$ & $\mathbf{1 2}$ & $\mathbf{2 2}$ & $\mathbf{3 0}$ & \\
\hline
\end{tabular}

The row-sum and the column-sum from the comprehensive decision matrix and the score for each $\mathbf{c}_{\mathbf{i}}$ are as below

\begin{tabular}{|c|c|c|c|}
\hline & Row-sum & $\begin{array}{c}\text { Column- } \\
\text { sum }\end{array}$ & Score \\
\hline $\mathrm{m}$ & $\mathbf{2 1}$ & $\mathbf{1 5}$ & 6 \\
\hline $\mathrm{e}$ & $\mathbf{2 5}$ & $\mathbf{1 1}$ & 14 \\
\hline $\mathrm{c}$ & $\mathbf{2 4}$ & $\mathbf{1 2}$ & 12 \\
\hline $\mathrm{p}$ & $\mathbf{1 4}$ & $\mathbf{2 2}$ & -8 \\
\hline $\mathrm{h}$ & $\mathbf{6}$ & $\mathbf{3 0}$ & -24 \\
\hline
\end{tabular}


Here we find that the maximum score is obtain by $\mathbf{e}$, that is by the course ENGINEERING .

Hence Mr X can choose the course ENGINEERING for his son.

\section{CONCLUSION}

Thus we see that Fuzzy soft set theory is very much interesting and useful for solving the day to day problems. It helps to take decision making in a critical situation .

\section{REFERENCE}

[1] L.A.Zadeh,Fuzzy set,Information and control 8, 338353(1965)

[2] D.Molodtsov ,Soft set Theory -First Results, Computer and Mathematics with Applications 37 (1999) 19-31

[3] Z. Pawlak, Rough Sets, International journal of Information and Computer Sciences 11, 341-356, (1982)

[4] P.K.Maji , A.R.Roy and R.Biswas , An Application of Soft sets in A Decision Making Problem, Computer and Mathematics with Applications 44 (2002) 10771083.

[5] Tutut Herawan, Soft Set Based Decision Making For Patients Suspected Influenza-Like Illness, International journal of Modern Physics :Conference series Vol.1 no $.1(2010) 1-5$

[6] N. Cagman , S Enginoglu and F.Citak, Fuzzy soft setTheory And Its Application, International journal of Fuzzy systemsVol.8 No. 3 (2011) pp 137-147 .

[7] P.K.Das and R.Borgohain , An Application of Fuzzy Soft Set in Multicriteria Decision Making Problem, International journal of Computer Applications (09758887)Vol. 38 No 12 ,January 2012 .
[8] Prabitra Kumar Maji , A neutrosophic soft set approach to a decision making problem , Annuals of Fuzzy Mathematics and Informatics , Vol.3 , No.2 , (April 2012) pp.313-319

[9] Ayman Hazaymeh , I.B.Ablullah , Z. Balkhi and Rose Ibrahim , Applied Mathematical Sciences Vol. 6 2012, No.112, 5547-5564

[10] Shawkat Alkhazaleh and Abdul Razak Salleh , Fuzzy Soft Multiset Theory, Abstract and Applied Analysis, Vol.2012

[11] Sudhir K. Pundir ,Rimple Pundir, Fuzzy Sets and Their Applications , Pragati Prakashan ,Third Edition 2010 .

[12] T.Y.Lin , A set theory for soft computing , a unified view of fuzzy sets via neighborhood, In proceedings of 1996 IEEE International conference of fuzzy systems .New Orleans .LA, September 8-11 , pp.1140-1146 ,(1996)

[13] D.Chen,E.C.C.Tsang,D.S.Yeung and X.Wang,The parameterization reduction of soft sets and its applications , Comput.Math.Appl. 49(2005), 757-763. ,

[14] A.Rosenfeld ～， Fuzzy Groups J.Maths.Anal.Appl.35(1971)512-517

[15] R.Biswas,S.Nanda ,Rough groups and rough subgroups , Bull.Polish Acad.Math. 42(1994).

[16] T.Y.Lin , A set theory for soft computing , a unified view of fuzzy sets via neighborhood, In proceedings of 1996 IEEE International conference of fuzzy systems .New Orleans .LA, September 8-11 , pp.1140-1146, (1996 ) 251-254 